\title{
Stability analysis of dredging the flow sediment regiment upstream a dam
}

\author{
G. Akbari \\ Civil Engineering Department, University of Sistan \& Baluchestan, Iran
}

\begin{abstract}
The overall aim of this study was to investigate stability of flow-sediment regime upstream from a dam, to develop and calibrate a one-dimensional flow-sediment transport numerical model to deal with the many river-reservoir sedimentation problems including river reservoir dredging upstream from a dam. The basic physical principles of the conservation of mass and momentum are used to describe the fluid flow. The conservation of mass and semi-empirical equations governing sediment particle movement are adopted to establish the interaction between the sediment movement and fluid flow. The resulting mathematical formulation is highly non-linear and complex. It is impractical, if not impossible, to solve them analytically. Therefore the three governing equations of water continuity, sediment continuity, and momentum were solved numerically. The three governing equations were solved in an approximate linear form as well as in the more complete non-linear form. Also, by ignoring certain terms, the sediment continuity equation was uncoupled from the other two. Algorithms were developed for linear or non-linear and coupled or uncoupled solutions. Keywords: dredging upstream, linear, non-linear, coupled, uncoupled, watersediment phases.
\end{abstract}

\section{Introduction}

In recent years, many major projects have caused serious difficulties as proper account has not been taken of their relationship with the surrounding environment. It has been estimated that nearly 14000 mega tonnes of sediment is carried annually by rivers worldwide and is deposited in man made reservoirs. This reduces the capacity of reservoirs which leads to an equivalent loss of 6 billion dollars per annum [5]. Dredging river reservoir upstream a dam is a 
necessary measure for stabilizing river flow condition upstream a dam. This can slow down the energy when the release of sediment free water from the dam results in considerable downstream erosion of banks and riverbeds. The release of clear water from the Imperial dam after its closure in 1938 caused the scour of large amounts of sand and silt from the riverbed downstream, creating large difficulties. The same is the case at Hoover, Parker, Garison and many dams worldwide. Due to the erosion downstream of the Senner Dam located south of Khartoum in the Sudan, the costs of repairs are assessed to be around 16 million dollars which will be more than the original cost of the dam [6]. The sedimentfree water below the dam flows faster and tends to re-acquire a normal sediment load. The resulting erosion may be dangerous for the foundations of hydraulic structures existing downstream of the dam and dam itself. For example the resulting erosion downstream of Aswan High Dam threatens to undermine the foundations of 3 dams and 550 bridges between the Aswan High Dam and the sea [2]. However, case studies of past projects show that the effects of changes in flow regimes can help in comprehensive planning of the dam and reservoir projects and environmental losses can be controlled. The construction of the Trans Florida Barrage Canal was abandoned in the USA because from the calculations it was felt that adverse environmental effects due to the changes in the river regime outweighed the proposed benefits.

\section{Simulation of sediment-laden flow upstream a dam}

Numerical models can be used to predict the water-surface profile during floods, the effect of river engineering works at one location on the rest of the system, and long-term maintenance requirements. Sediment transport phenomena are very complex and time variant even when the flows are steady. For example flow upstream and downstream of newly constructed obstruction or flow in a newly dredged channel until regime conditions is achieved. To simulate timedependent transient flow in open channels, the unsteady flow of sediment-laden water can be formulated in terms of three one-dimensional partial differential equations. These equations can be represented as:

Modified St. Venant Eqn. for sediment mass flow:

$$
\partial Q s / \partial x+p_{o r} \partial A d / \partial t+\partial A C s / \partial t=q_{l s}
$$

Modified St. Venant Eqn. for water mass flow:

$$
\partial Q / \partial x+\partial A / \partial t+\partial A d / \partial t=q_{l}
$$

Modified Hydro dynamic St. Venant Eqn. for sediment-laden mass flow: $\rho \partial Q / \partial t+\beta \partial / \partial x\left[\rho Q^{2} / A+\rho g A / T d A / \partial x-\rho g A\left(S-S_{f}\right)-\rho q_{l} Q / A+\right.$

$$
\rho Q / A \partial A d / \partial=0
$$

The different parameters used in above equations are: $\boldsymbol{Q}$ is the discharge; $\boldsymbol{A}$ is the area of cross-section; $\boldsymbol{A}_{\boldsymbol{d}}$ is the volume of sediment deposited/eroded per unit 
length of channel; $\boldsymbol{x}$ is the distance along the channel; $\boldsymbol{t}$ is the time; $\boldsymbol{q}_{\boldsymbol{l}}$ is the lateral flow per unit length of channel; $\beta$ is the momentum correction factor; $\boldsymbol{g}$ is the acceleration due to gravity; $\boldsymbol{T}$ is the channel top width; $\boldsymbol{S}$ is the bed slope and $\boldsymbol{S}_{\boldsymbol{f}}$ the friction slope; $\boldsymbol{Q}_{\boldsymbol{S}}$ is the sediment discharge, $\boldsymbol{C}_{\boldsymbol{S}}$ is the sediment concentration $=\boldsymbol{Q}_{\boldsymbol{S}} / \boldsymbol{Q}, \boldsymbol{p}_{\boldsymbol{o r}}$ represents the volume of sediment in unit volume of bed layer and $\boldsymbol{q}_{\boldsymbol{l}}$ is the lateral sediment flow. The friction slope $\boldsymbol{S}_{\boldsymbol{f}}$ and sediment load $\boldsymbol{Q}_{\boldsymbol{S}}$ need to be defined by what may be called the supplementary equations (see [6]). Prior knowledge of some of the parameters embedded in these supplementary equations is required in order to route flow and sediment down a river reach.

\section{Flow-sediment dredging upstream}

A steady flow problem involving dredging upstream was attempted to investigate the relative performances of the four different numerical solutions. The same data used here are as follows.

\subsection{Channel characteristics}

A wide rectangular channel was selected. The reach length was taken as $20 \mathrm{~km}$ with special increment of $\Delta \mathrm{x}=500 \mathrm{~m}$ and the bed slope, $\mathrm{S}=0.0005$. The initial flow was assumed to be $5 \mathrm{~m}^{3} / \mathrm{s}$ per unit width at the upstream end. The normal initial depths were assumed as $3 \mathrm{~m}$ and then the depth at the upstream end was made $5 \mathrm{~m}$ due to the dredging of $2 \mathrm{~m}$.

\subsubsection{Upstream boundary condition}

A steady flow of $5 \mathrm{~m}^{3} / \mathrm{s}$ per unit width was imposed (U/S boundary condition), and a second boundary condition was defined by using a constant bed level condition at node- 1 .

\subsubsection{Downstream boundary condition}

The downstream boundary condition was defined by the Manning's equation.

\subsubsection{Frictional slope}

It is possible to use any roughness equation such as Chezzy, Colebrook-White, or Manning formula to estimate riverbed roughness. For this case study, the frictional slope was calculated by a general form of Manning equation as follows.

$$
S_{f}=\left[\alpha Q / A R^{\beta}\right]^{2}
$$

where, $S_{f}$ is bed resistance, $\alpha$ and $\beta$ are empirical parameters need to be adjusted, $Q, A, R$ are flow discharge, cross sectional area, and hydraulic radius respectively. 


\subsubsection{Sediment characteristics}

A uniform sediment bed material was selected. The value of volume of sediment per unit volume of bed layer, $\mathrm{p}_{\text {or }}$, was 0.8 , and effective grain size $\left(\mathrm{d}_{35}\right)$ was taken as $0.8 \mathrm{~mm}$. Sediment discharge, $\mathrm{Q}_{\mathrm{S}}$, was calculated using the simple equation as follows.

$$
Q_{S}=\alpha(Q / A)^{\beta} Q / y d_{m}^{\gamma}
$$

where, $\alpha, \beta$ and $\gamma$ are the sediment parameters to be optimized. Such simplified forms of the equations are acceptable when the parameters are specifically fitted to a particular situation by optimization methods [6]. The bed level at the upstream end was dredged by $2 \mathrm{~m}$.

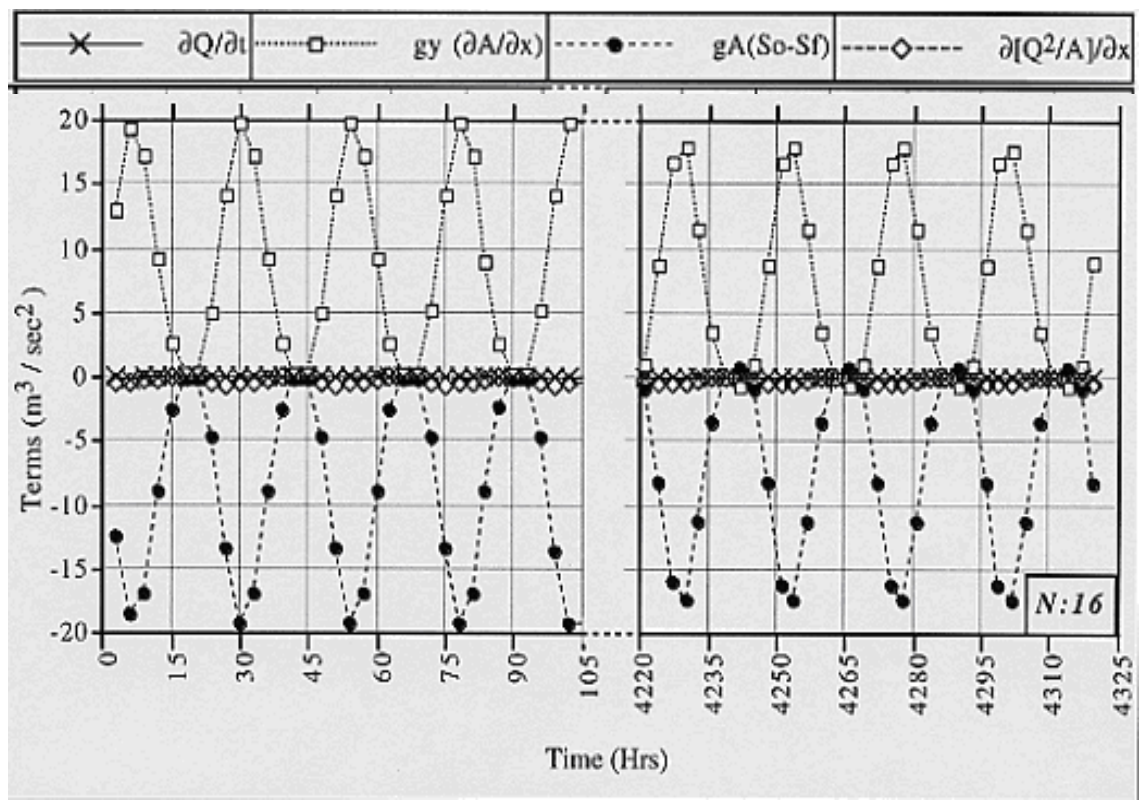

Figure 1: Magnitude of non-linear terms in the flow-sediment equation.

\section{Results and discussion}

Comparison of results for different models is shown in figures 2 to 5 . As can be seen, all of the models developed by author produced stable flow-sediment configuration. In particular the implicit non-linear and linear solutions are not significantly different for stable flow-sediment regime upstream a dam. This means that the linearization of the non-linear terms in the governing equations (1-5) did not affect the result, because the second and higher order partial differential terms of each variable between two successive nodes were so small for each time step. This confirms that when flow-sediment regime was stable, no 
large spatial or/and temporal changes occurred in the variables $\mathrm{Q}, \mathrm{A}, \mathrm{A}_{\mathrm{d}}$ etc., the errors due to ignoring the derivatives of non-linear terms $\left[\partial\left(\mathrm{Q}^{2} / \mathrm{A}\right) / \partial \mathrm{x}\right.$ and $\mathrm{gA} / \mathrm{T}$ $(\partial \mathrm{A} / \partial \mathrm{x})]$ in the momentum equation was insignificant. The linear models (LCM and LUM) can therefore be used here as satisfactorily as the non-linear (NCM and NUM) models. De-coupling the hydraulic and sediment variables in the uncoupled models, may lead to an ill-posed problem for which a general boundary condition cannot be satisfied. However, an upstream boundary provided constant discharge to the system, with the sufficient initial conditions, may result in a well-posed problem. That is also the reason why coupled and uncoupled models bring stable results. Further analysing the results shown in the figures, it shows that for dredging upstream, coupling and uncoupling the system of equations only had very little effect on the solution at the upstream end. This is due to the boundary condition at the upstream, which is mainly affected by the dredging at the upstream. Also as discussed earlier, the sediment continuity and momentum equations are implicitly coupled through the bed and frictional slope terms in the momentum equation.

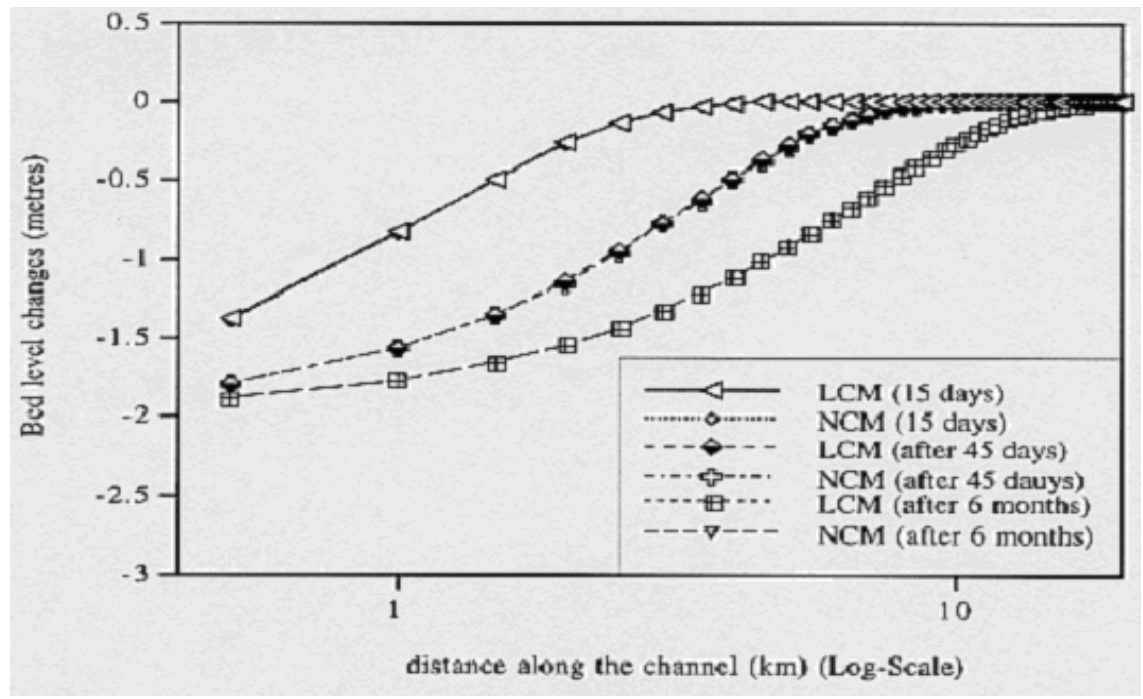

Figure 2: Comparison of coupled linear/non-linear models stable regime upstream.

For a stable flow regime the result of uncoupled models has shown satisfactory results, but the general problem with the uncoupled models is that they are unable to satisfy an arbitrary boundary condition. This is because the uncoupled solution of the equations (2) and (3) gives Q and A values at all nodes, from which $A_{d}$ values are determined using equation (1). Different numerical solutions were implicated can differ from each other in one way or another, for instance non-linear/linear implicit coupled and uncoupled models are quite different solution techniques. 


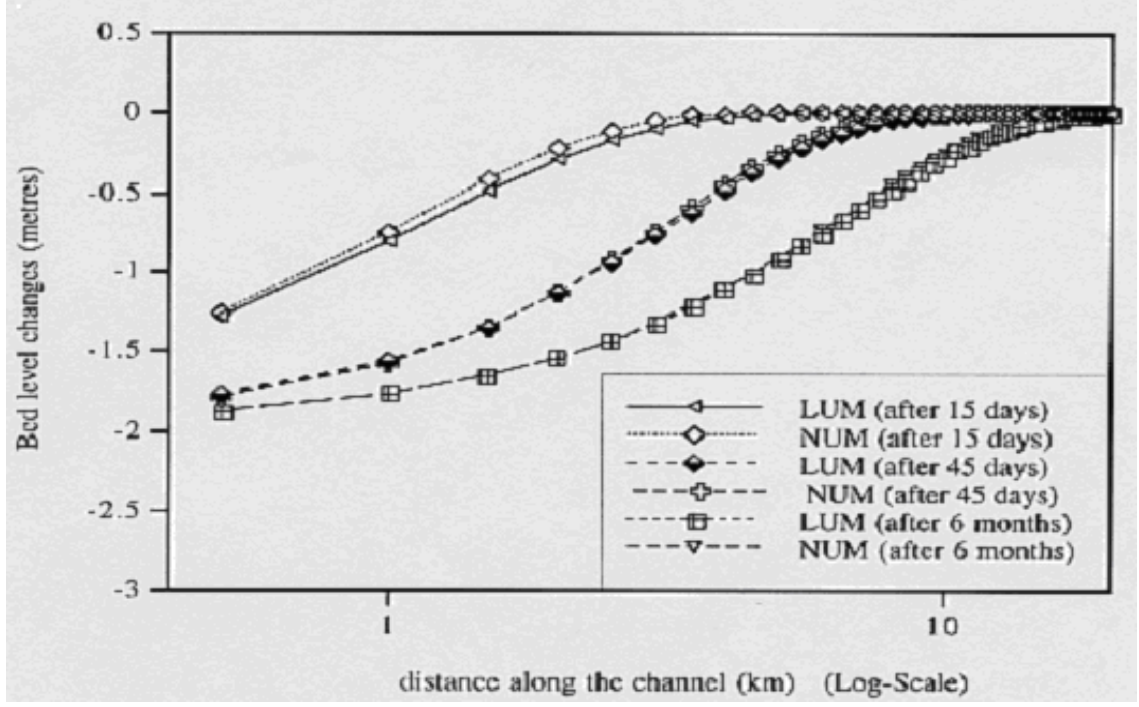

Figure 3: Comparison of uncoupled models stable regime upstream a dam.

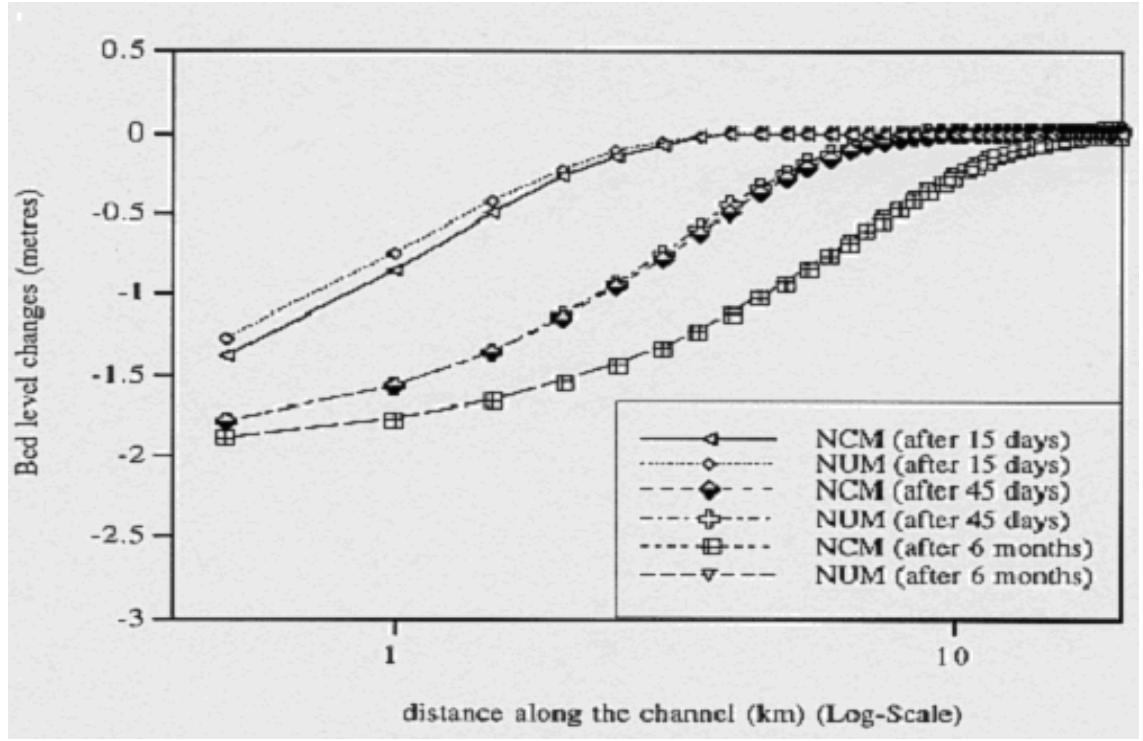

Figure 4: Comparison of coupled uncoupled non-linear models stable regime upstream.

However, when applying these models to a particular case (e.g. the stable flow regime upstream) they have almost the same results. This is mainly because of the implicit coupling in the uncoupled models through bed and frictional 
slopes in the momentum equation [bed and frictional slopes are treated in a similar way to other variables and discredited by weighted approximations in an implicit scheme. A conclusion may reach here that for some cases (e.g. the case study at the hand) neither the non-linear nor linear implicit solution to the governing equations can be better than the others. Because, each of these model could produce almost the same result, when the same values of the parameters $\Delta \mathrm{x}$ and $\Delta \mathrm{t}$ were used.

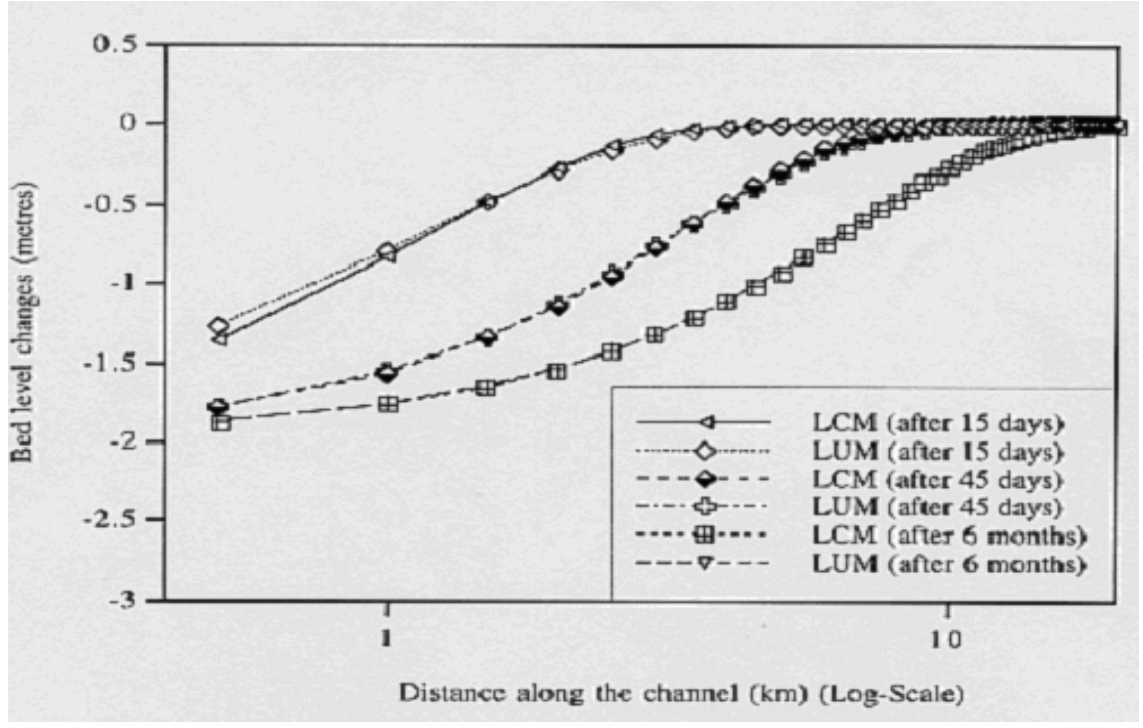

Figure 5: Comparison of coupled uncoupled linear models stable regime upstream.

\section{References}

[1] Ackers, P., and White, W.R., "Sediment Transport-New Approach and Analysis," Journal of the Hydraulics Division, ASCE, Vol. 99, No. HY11, November, 1973, 2041-2060.

[2] Akbari, G.H., Wormleaton, P.R., Ghumman, A.R., "A Numerical Model for Estimation of Sedimentation in Reservoirs," Proceedings of International Conference on Aspects of Conflicts in Reservoir Development and Management, pp. 731-41, City university, London, 3-5 Sept. 1996.

[3] Akbari, G.H., Wormleaton, P.R., Ghumman, A.R., "A Simple Bed Armoring Algorithm for Graded Sediment Routing in Rivers", Water for a Changing Global Community, 27th IAHR Congress, 10-15 August 1997 San Francisco, USA. 
[4] Akbari, G.H., "Sensitivity analysis of flow-sediment transport parameters", 6th Seminar of Iranian students in Europe, UMIST, Manchester, UK, 1999.

[5] Akbari, G.H., "Fully coupled non-linear mathematical model for flowsediment routing through rivers", $\mathrm{PhD}$ Thesis, Q.M. University of London, 2003.

[6] Chin, C.O., Melville, B.W., Raudkivi, A.J. “Armoring Development” J. Hyd. Engg. ASCE, Vol. 120, No. 8, pp. 899-918, 1994.

[7] Correia, L.P. "Numerical Modeling of Unsteady Channel Flow Over a Mobile Boundary", These No 993 (1992), Ecole Polytechnique Federal De Lausanne.

[8] Fisher, K.R. "Manual of Sediment Transport in Rivers" HR, Wallingford Report SR 359, May 1995.

[9] Ghumman A. R, Wormleaton P.R, Akbari G.H, "Estimation of Changes in Flow Regimes After Construction of a Dam", Proceedings of International Conference on Aspects of Conflicts in Reservoir Development and Management, pp. 749-55, 3-5 Sept, London, 1996.

[10] Ghumman A. R, Wormleaton P.R, Hashmi H.N, Akbari G.H, "Parameter identification for Sediment Routing in Rivers" IAHR, Journal of Hyd. Research, Vol. 34-1996.

[11] Little, W.C., Mayer, R.G., "The Role of Sediment Gradation on Channel Armoring”, Pub. No. ERC-0672, School of Civil Engg, Georgia Instit. Of Technology, Atlanta, Georgia, 1972.

[12] NAG, "NAG Fortran Library Manual”, QMW, Univ. of London, 1985.

[13] Nakato, T. "Tests of Selected Sediment Transport Formulae", J. Hyd. Engg, ASCE, Vol. 116, No. 3, pp. 362-379, 1990.

[14] Wormleaton, P.R., Ghumman, A., R., and Akbari G., H., "A Comparison of the Performance of Coupled/Uncoupled Non-linear Models for Sediment Routing in Rivers", Proceedings of the Regional Conf. on Water Resources Management (WRM 95), Isfahan, Iran, 1995.

[15] Wormleaton, P.R., Ghumman, A., R., and Akbari G., H., "Degradation Numerical Models for the Missouri River", Proceedings of International Conference on Aspects of Conflicts in Reservoir Development and Management, pp. 759-67, 3-5 Sept, London, 1996. 